\title{
MIND-READING AND METACOGNITION: NARCISSISM, NOT ACTUAL COMPETENCE, PREDICTS SELF-ESTIMATED ABILITY
}

\author{
Daniel R. Ames and Lara K. Kammrath
}

\begin{abstract}
In this paper, we examine the relationship between people's actual interpersonal sensitivity (such as their ability to identify deception and to infer intentions and emotions) and their perceptions of their own sensitivity. Like prior scholars, we find the connection is weak or non-existent and that most people overestimate their social judgment and mind-reading skills. Unlike previous work, however, we show new evidence about who misunderstands their sensitivity and why. We find that those who perform the worst in social judgment and mindreading radically overestimate their relative competence. We also find origins of these self-estimates in general narcissistic tendencies toward self-aggrandizement. We discuss evidence from two studies, one involving the Interpersonal Perception Task (the IPT-15) and another focusing on inferences about partners after a faceto-face negotiation exercise. In both cases, actual performance did not predict self-estimated performance but narcissism did.
\end{abstract}

KEY WORDS: empathic accuracy; interpersonal sensitivity; metacognition; mindreading; narcissism.

Understanding what others think, want, and feel is essential to interpersonal sensitivity and, by extension, to social life. When people fail to read others' minds, they form incorrect impressions, take ineffective or inappropriate actions, and generally fail to coordinate their behavior with the attitudes and behavior of those around them. But do people know when they misread minds or misjudge others? Mounting evidence suggests that people are often poor at estimating their own competence in domains ranging from logical reasoning to sense of humor (e.g., Dunning, Johnson, Ehrlinger, \& Kruger, 2003). This effect apparently extends to

\footnotetext{
Daniel R. Ames is affiliated with Department of Management, Columbia Business School.

Lara K. Kammrath is affiliated with Department of Psychology, Columbia University.

The authors thank Rick Larrick, Del Paulhus, and Paul Rose for helpful comments about this research and the manuscript.

Address Correspondence to Daniel Ames, Columbia Business School, 3022 Broadway Avenue, New York, NY 10027; e-mail: da358@columbia.edu.
} 
interpersonal sensitivity where a number of researchers (e.g., Davis \& Kraus, 1997; Ickes, 1993; Realo et al., 2003) have found weak or absent connections between people's confidence in their empathic abilities and their actual success in inferring another person's mental states.

In this paper, we consider self-assessments of interpersonal sensitivity and mind-reading. Bridging recent work in metacognition and empathic accuracy, we find that those who perform worst at reading minds greatly overestimate their ability. We also go beyond existing accounts by tracing these fallible estimates to what may be the most broad-based belief concerning one's own comparative ability: narcissism. In two studies, we show that narcissistic tendencies toward self-aggrandizement have an important effect on a person's assumptions of interpersonal sensitivity in various contexts.

\section{Self-assessments and Metacognition}

Before considering research on interpersonal sensitivity and social judgment, we briefly review recent work on basic questions in self-awareness: are people generally aware of their own traits and abilities ... and if not, why? We believe that recent answers to these questions have the potential to help scholars of interpersonal sensitivity better model when and how perceivers fail to understand their own social competence.

A good deal of research over the past few decades suggests that very often self-awareness is not only limited (e.g., Paulhus, Lysy, \& Yik, 1998) but also distorted in the direction of flattering and enhancing oneself (e.g., Alicke, 1985; Dunning, Meyerowitz, \& Holzberg, 1989; Taylor \& Brown, 1988). While the positive and negative consequences of such distortions continue to be debated (e.g., Colvin \& Block, 1994), there seems to be reasonable consensus that self-awareness is far from perfect in many, and perhaps most, domains.

In recent years, work by Dunning, Kruger, and colleagues (e.g., Ehrlinger \& Dunning, 2003; see Dunning et al., 2003 for a review; Kruger \& Dunning, 1999) has focused on the ability to gauge one's relative taskperformance, an ability they term metacognition. They have argued that the incompetent suffer a "double curse": those who perform poorly in a domain are not only unskilled, they are unaware of their lack of skill. The relationship between perceived performance and actual performance-both absolute and relative to peers-is often meager. A typical pattern of results in this work shows those in the lowest quartile of actual performance extensively overestimating their performance, often placing 
themselves somewhere near the 60th percentile-which is to say, seeing themselves as above average. In contrast, while those in the top quartile sometimes show higher estimates than those in lower quartiles, they generally tend to underestimate their relative performance.

Metacognition scholars have suggested several mechanisms at work. First, they argue that competence itself can be a prerequisite for judging one's relative performance. By definition, then, those who are less competent in a domain also lack the ability to recognize what good performance would look like. Kruger and Dunning (1999) highlighted this effect by showing that among those least skilled in problem solving, perceptions of performance declined after subsequent training in the domain: as competence increased, these perceivers seemed to show a growing awareness of their limited skills.

In addition, research suggests a second mechanism involving domain specific self-concepts (i.e., prior beliefs about one's skills in a domain). Ehrlinger and Dunning (2003), for example, showed that chronic views of one's own logical reasoning skill were unrelated to actual performance on a specific reasoning task but did predict self-perceived relative performance. In sum, competence may be necessary to effectively diagnose one's own relative skill and chronic self-views may often color estimates of one's own specific performances.

\section{Metacognition and Interpersonal Sensitivity}

Numerous scholars of empathy and interpersonal sensitivity have found results parallel to those described above: people rarely have accurate impressions of their own mind-reading abilities. In the domain of deception, researchers have found that perceivers' confidence in detecting lies is often unrelated to actual performance and, further, is generally overstated (DePaulo, Charlton, Cooper, Lindsay, \& Muhlenbruck, 1997; Ekman \& O'Sullivan, 1991). In the realm of trait judgments, Swann and Gill (1997) have concluded that "the confidence that people have in their impressions of others is, at best, sporadically related to the accuracy of those impressions." (p. 755) In work on empathy, Hodges (2003) has shown that people mistakenly assume they better understand those who have been through similar experiences, such as childbirth, even though no differences in actual sensitivity are apparent.

Recent work by Realo et al. (2003) revolves around a similar theme. Realo and colleagues analyzed the structure of perceivers' beliefs about their ability to intuit others' traits, mental states, roles/status, and future 
behaviors. A single structure emerged, suggesting that perceivers' chronic self-views generalized across these domains. However, these self-views were entirely unpredictive of actual performance on a number of social judgment tasks, including inferring emotions from pictures of faces and speech as well as judging traits from brief videos of interviews with targets (Realo et al., 2003).

A few scholars of interpersonal sensitivity have found modest withinperceiver connections between accuracy and confidence. For instance, and Smith, Archer, Costanzo (1991) and Patterson, Foster, and Bellmer (2001) found that participants, on balance, showed small but positive links between accuracy and confidence across their judgments of social scenes. Nonetheless, the bulk of evidence suggests that metacognition about interpersonal sensitivity is far from perfect, as underscored in reviews by Ickes (2003, Chapter 7) and Davis and Kraus (1997) who found that self-reported measures of social sensitivity generally failed to predict actual empathic accuracy. After surveying the results, Ickes (2003) observed that "most perceivers may lack the kind of metaknowledge they would need to make valid self-assessments of their own empathic ability." (p. 172)

\section{Our Approach}

These prior perspectives are provocative, but leave two major questions unanswered that we tackle in the present work.

The first major question concerns not just the general lack of selfawareness in interpersonal sensitivity but who is unaware in what way. Ickes (1993), Davis and Kraus (1997), and Realo et al. (2003) found weak or absent links between self-perceived performance and actual performance in empathic accuracy. However, these reports of "non-relationships" do not reveal whether those least skilled in empathic accuracy tend to substantially overestimate their abilities. If this is the case, as work by metacognition scholars (e.g., Dunning et al., 2003) would suggest, those most limited in interpersonal sensitivity may be the least aware of their limitations and potential need for improvement. An alternative might be that those who are insensitive are just as likely to know it, but simply fail to care. Those interested in education and intervention may have a considerable stake in this distinction. We follow Dunning and colleagues in expecting a significant effect among the unskilled: not only will estimated and actual ability be weakly correlated, but those worst at reading minds will also vastly overestimate their ability. 
A second issue focuses on the source of assumed ability: from where do these questionable assumptions come? While Ehrlinger and Dunning (2003) and Realo et al. (2003) have considered chronic self-views in particular domains (e.g., beliefs about logical reasoning ability), they have not examined whether global self-concepts may be at work. Recent research suggests that narcissism might be seen as the global chronic selfview about one's competence relative to others (see, e.g., Morf \& Rhodewalt, 2001 and adjacent commentaries). Importantly, the narcissistic self-concept is not grounded in any specific performance domain but rather focuses on one's own very general sense of comparative abilities and worth. Narcissism can be seen as a continuous dimension which, in varying degrees, entails "unrealistically exaggerated beliefs about ... abilities and achievements" (John \& Robins, 1994) and "pervasive patterns of grandiosity and self-importance" (Morf \& Rhodewalt, 2001). Those who score high in narcissism tend to have overly positive interpretations of their particular attributes and performances, including intelligence and attractiveness (e.g., Gabriel, Critelli, \& Ee, 1994), positive personality traits (e.g., Paulhus, 1998), and performance in group discussions (e.g., Robins \& John, 1997).

Even though narcissism does not revolve around interpersonal sensitivity (and even though some scholars have suggested that narcissists may be less interpersonally sensitive than others, e.g., Watson, Grisham, Trotter, \& Biderman, 1984), we believe that narcissism will positively predict self-estimates of social judgment ability in concrete tasks. We expect this effect will emerge beyond any effect of actual performance and beyond the effect of more focused self-view constructs that are specific to the domain of interpersonal perception (e.g., self-monitoring). Evidence for such a mechanism would give a new perspective on interpersonal sensitivity as well as metacognition more generally. As noted earlier, knowing how and why people (mis)perceive their interpersonal sensitivity is crucial for increasing interpersonal sensitivity - a topic we return to in the Conclusion.

Our work also makes a noteworthy design departure from prior research. Across our set of approximately 150 participants, we have a measure of narcissism as well as domain-specific self-concepts (e.g., selfmonitoring), and actual and estimated performances on three interpersonal judgment tasks (including judgments about video stimuli as well as the inference of intentions and emotions for a face-to-face interaction partner). This dataset affords a unique perspective on how general and domain-specific self-concepts relate to one another and to performance estimates as well as on how performance estimates and actual performances correlate within participants across tasks. 
To summarize, we believe that gauging one's own interpersonal sensitivity is a considerable challenge-one that most people meet with very limited success. In particular, we believe that those who show the lowest levels of sensitivity will substantially overestimate their relative skill. Moreover, we believe that these estimates of skill will show consistency across tasks (even if performance is inconsistent) because they are partly driven by narcissistic global self-concepts.

\section{Plan of Study}

We tested these predictions in two studies conducted on the same adult participant population. In the first study, we administered a standardized empathic accuracy task, the IPT-15, and gathered data about actual performance as well as self-estimates of performance. In the second study, participants completed a negotiation exercise in pairs, after which they recorded their own intentions and feelings and estimated their partner's intentions and feelings. This allowed us to compare indices of their accuracy in intuiting their partner's mental states with their self-estimated performance in doing so. We also collected individual difference measures from our participants, giving us the opportunity to look at connections between narcissism, self-monitoring, and other constructs across the estimated and actual performances (e.g., to test whether self-monitoring or another construct specific to interpersonal perception would mediate the effects of narcissism).

\section{Study 1}

Our first study considers participants' performance on a standardized interpersonal sensitivity task (the IPT-15) involving social judgments about video clips with objectively true criteria, such as which of two conversants is the other's boss. Participants' actual sensitivity was compared with their estimates of their relative ability; we expected a weak or absent link. Individual difference measures were also collected to test predictions about the sources of performance estimates. We expected narcissism to predict such assumptions of sensitivity, though we included several other constructs that have received attention as possible predictors, including extraversion, self-monitoring, gender, and a social skills measure. We also included a measure of self-esteem to clarify that the self-aggrandizing effects of narcissism were distinct from basic feelings of self-worth. Our 
prediction was that narcissism would predict performance estimates above and beyond any effect of these other constructs.

\section{Method}

A total of 143 students (35 women; mean age was 28.4 years) in three Master's of Business Administration courses completed the Interpersonal Perception Task materials for Study 1 as well as individual difference measures used in analyses of both Studies 1 and 2.

Individual difference materials. The individual difference measures included five constructs: self-monitoring, extraversion, narcissism, selfesteem, and a social skills subscale of an autism-spectrum inventory. Selfmonitoring was measured with the 13 items used by Lennox and Wolfe (1984), including a subscale for self-presentation (e.g., "In social situations, I have the ability to alter my behavior if I feel that something else is called for") and a subscale for sensitivity to others (e.g., "I am often able to read people's true emotions correctly through their eyes" ${ }^{\prime \prime}$. Items were rated on a six-point scale ranging from "Certainly always false" (1) to "Certainly always true" (6).

Extraversion was measured with the eight-items for extraversion from the Big Five Inventory (John, Donahue, \& Kentle, 1991). Participants rated items extending from the stem "I see myself as someone who ..." on a scale ranging from "Disagree strongly" (1) to "Agree strongly" (5). Items included "is talkative," "is reserved" (reversed), and "is full of energy."

Narcissism was measured with a 16 item-pair scale by Ames, Rose, and Anderson (2004), drawing items in each of the four factors of Emmons' (1987) measure (Leadership/Authority, Self-Absorption/SelfAdmiration, Superiority/Arrogance, and Exploitiveness/Entitlement). For each pair, participants were told to "indicate which statement comes closest to describing your feelings and beliefs about yourself." Item pairs included "I really like to be the center of attention" + "It makes me uncomfortable to be the center of attention" and "I like having authority over people" + "I don't mind following orders."

Self-esteem was measured using the Robins, Hendin, and Trzesniewski (2001) single-item self-esteem scale. Participants indicated agreement with the statement "I have high self-esteem" on a scale ranging from "Disagree strongly" (1) to "Agree strongly" (5).

The social skills measure was taken from the Baron-Cohen, Wheelwright, Skinner, Martin, and Clubley (2001) Austism-Spectrum Quotient scale. Participants rated the 10 items assessing social skill (e.g., 
"I prefer to do things with others rather than on my own," "I find social situations easy") on a scale ranging from "Definitely disagree" (1) to "Definitely agree" (4).

The interpersonal perception task. The IPT-15 or Interpersonal Perception Task-15 (Costanzo \& Archer, 1989, 1993) is a collection of 15 naturalistic scenes, with one to four individuals in each scene. Scenes last from roughly $30 \mathrm{~s}$ to $2 \mathrm{~m}$ in length. For each scene, there is an objectively correct answer to a question about the people in the scene (e.g., one scene shows a short interaction between two people and then the viewer is asked to judge which of the two is the other's boss; in another scene, two personal monologues by an individual speaker are shown back-to-back and the viewer is asked to decide which, if either, features the speaker telling the truth). The scenes contain no obvious verbal information for answering the questions. Five different types of scenes are featured (three of each), including kinship, intimacy, deception, competition, and status. The IPT-15 has been employed by numerous nonverbal behavior scholars as a meaningful measure of interpersonal sensitivity (e.g., Smith, et al., 1991; Patterson \& Stockbridge, 1998; Patterson et al., 2001).

Procedure and estimated performance measure. Participants completed the IPT materials individually as part of a class exercise. For each scene, participants viewed the relevant video clip and then indicated their response to the scene-specific question. At the end of the 15 scenes, without receiving any feedback about the correctness of their responses, participants were asked to indicate how they thought their performance compared to their average classmate as a percentile ranking.

The individual difference measures were administered as a separate exercise approximately 2 weeks after the IPT materials.

\section{Results}

In a small number of cases, participants did not complete all materials. Therefore, for the reported correlation results, valid Ns range from 138 to 143.

Reliabilities. The self-monitoring scale yielded $\alpha=.81$, while the self-presentation subscale had $\alpha=.80$ and the sensitivity-to-others subscale had $\alpha=.76$. The extraversion scale yielded $\alpha=.86$ while the narcissism scale yielded $\alpha=.67$. The social skills scale had $\alpha=.72$. The 15 items of the IPT yielded $\alpha=.44$. 


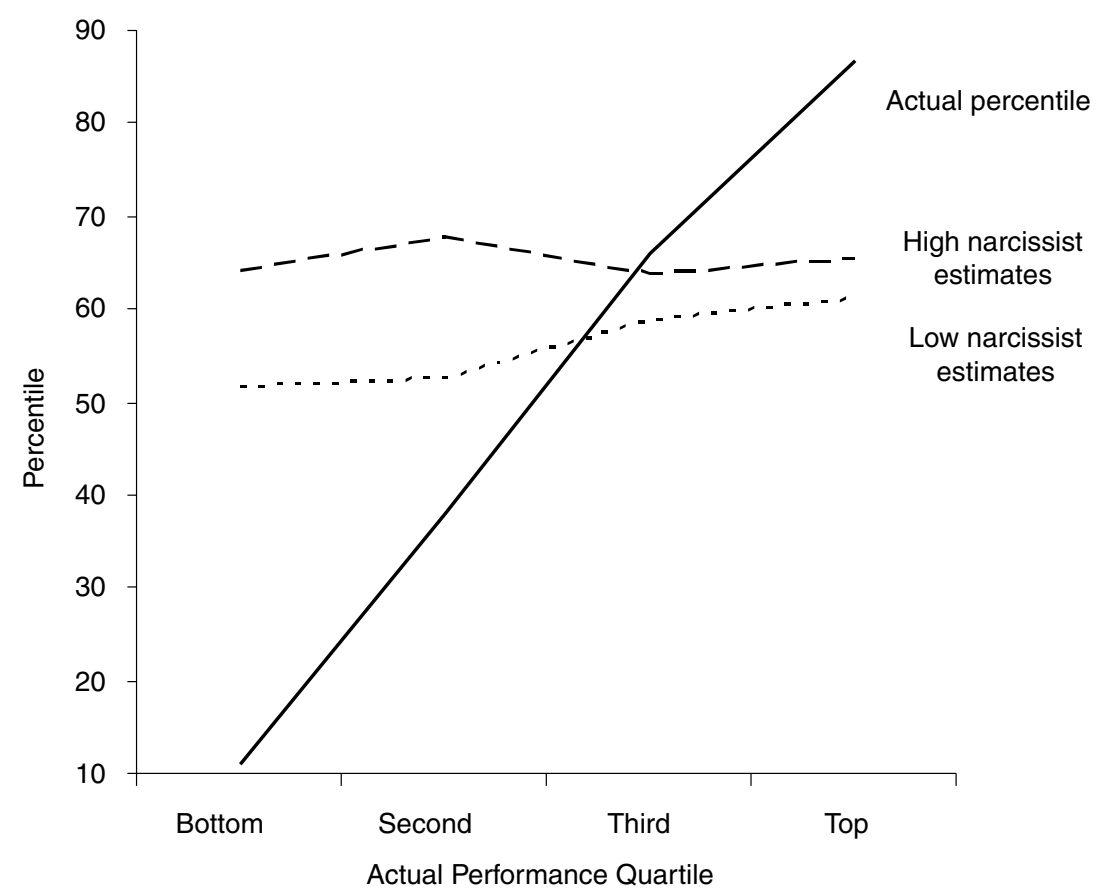

Figure 1. Estimated and actual performance on IPT (Median Split in Narcissism, Study 1).

Estimated vs. actual performance. We expected that participants' estimates of their percentile performance would not strongly correlate with their actual performance. Indeed, the correlation was $r=.15(p=$ $.08, n=140$ ). The mean estimated percentile was $60.1 \%$, significantly higher than the true mean percentile of $50 \%(t(140)=6.5, p<.001)$.

Dunning and colleagues (e.g., Dunning et al., 2003) have established a convention of describing metacognition results by splitting participants into quartiles of actual performance and, in most cases, highlighting the contrast between the worst performers (in the bottom quartile) and the best performers (in the top quartile) in terms of their estimated performance (see Figure 1). Applying this approach to our results, we see that, as predicted, participants in the bottom quartile dramatically overestimated their performance, expecting on average to fall in the 56th percentile while they actually averaged in the 10th $(D=46.2, t(39)=$ 
TABLE 1

Correlates of Estimated and Actual IPT Performance

\begin{tabular}{|c|c|c|}
\hline \multirow[b]{2}{*}{ Measure } & \multicolumn{2}{|c|}{ Correlations } \\
\hline & Estimated IPT percentile & Actual IPT percentile \\
\hline Narcissism & $.26^{* *}$ & .04 \\
\hline Self-monitoring & $.29 * *$ & .02 \\
\hline Sensitivity to others & $.29 * *$ & .00 \\
\hline Self-presentation & $.19^{*}$ & .03 \\
\hline Extraversion & $.28^{* *}$ & -.02 \\
\hline AQ social skill & $.30^{* * *}$ & -.06 \\
\hline Self-esteem & .11 & -.11 \\
\hline Gender $^{a}$ & .01 & .04 \\
\hline
\end{tabular}

15.0, $p<.001)$. This estimate was significantly higher than $50 \%(t(39)=$ $2.1, p<.05)$, highlighting that those individuals who performed worst still saw themselves as significantly "above average." In contrast, people in the top quartile actually underestimated their performance, expecting to fall in the 65th percentile when, in fact, they averaged in the 87th $(d=-22.0, t(26)=-9.2, p<.001)^{1}$.

Narcissism and estimated performance. While we did not expect a strong link between actual performance and estimated performance, we did expect narcissism to predict estimated performance. This was confirmed. As shown in Table 1, those higher in narcissism are more likely to think they performed well on the IPT-15 $(r=.26, p<.01, n=138)$. High self-monitors were also likely to estimate their performance highly $(r=$ $.29, p<.001)$. Finally, extraverts $(r=.28, p<.001)$ and people who scored highly on the social skills subscale of the AQ $(r=.30, p<.001)$ were also likely to think they did well on the IPT. Self-esteem was not related to estimated performance. Gender was not significantly related to actual or estimated performance or to narcissism.

Partialling out all of these other predictors (actual performance, sensitivity to others, self presentation, extraversion, social skill, self-esteem, 
and gender), narcissism remained a significant predictor of estimated competence (partial $r=.18, p<.05, n=138$ ).

Narcissism, actual performance, and self-awareness. Narcissism did not significantly predict actual performance $(r=.04, n s, n=138)$. Indeed, none of our measures significantly predicted actual performance on the IPT-15 (see Table 1).

Further, narcissism was not associated with self-awareness, as illustrated in Figure 1. In a multiple regression model predicting estimated performance with actual performance, narcissism, and an interaction of actual performance and narcissism, narcissism was significantly predictive $(\beta=$ $.34, t=2.47, p=.02)$, but actual performance and the interaction term were not significant $(\beta=.24, t=1.29, p=.29$ and $\beta=-.13, t=0.58, p=$ .57 , respectively). If high narcissists were less self-aware than low narcissists, this interaction term would have been significant and negative.

Narcissism was also not significantly related to a difference measure of estimated-minus-actual performance $(r=.13, n s)$. As can be seen in Figure 1, low performing narcissists appeared to be less well calibrated than non-narcissists while high performing narcissists appeared to be better calibrated than non-narcissists. As a result, there was no overall effect of narcissism on calibration.

\section{Discussion}

These results confirm our two major predictions. First, we found that not only were estimated and actual performance only weakly correlated, those who showed the lowest levels of interpersonal sensitivity on the IPT-15 substantially overestimated their ability. Second, we found that these estimates of ability were predicted by narcissism, even after controlling for the effects of other constructs focused specifically on the domain of interpersonal sensitivity (e.g., self-monitoring). Overall, narcissism had a main effect on estimated performance but was unrelated to both actual performance and self-awareness (see Figure 1).

\section{Study 2}

The results of Study 1 are encouraging, but the IPT-15 features a limited set of video stimuli and focuses on judgments of status, deception, and relationships. To more fully test our account, we sought a design that involved face-to-face interactions and that yielded judgments about 
others' intentions and emotions. Moreover, we wanted an interaction that was engaging and meaningful for participants. Study 2 provided this by relying on a dyadic negotiation exercise in which pairs spent 20 min or so resolving conflicting interests. After the interaction, our pairs recorded their own intentions and emotions as well as their assumptions about their partner's intentions and emotions. Participants also indicated their assumed relative performance on the mind-reading tasks, allowing us to compare estimated and actual performance.

Because nearly all of the participants in Study 2 also participated in Study 1 , these results could be compared, allowing us to examine consistency in performance as well as in estimates across tasks. This link also let us test our predictions about narcissism and other individual difference measures.

The negotiation exercise in Study 2 provided a highly engaging situation which the participants (MBA students) took very seriously. By measuring their satisfaction with the interaction, we were able to gauge the impact of actual interpersonal sensitivity-and to examine whether accurate mind-reading matters to interactions.

\section{Method}

A total of 164 students (43 women; mean age was 28.3 years) in three Master's of Business Administration courses completed the materials for Study 2 as well as individual difference measures described in Study 1. In Study 2, participants were randomly paired with a fellow student as part of a class exercise. Participants completed a negotiations exercise in which each adopted one of two roles: that of an entrepreneur selling his/her family business and that of an executive at a multinational company seeking to buy the entrepreneur's company. The negotiation began with the assumption that a general deal had already been reached and that the task at hand was to finalize several issues, such as the number of family members to be retained as employees once the company was acquired. These issues were "integrative" in the sense that some issues were more important to the seller (family employees retained) and others were more important to the buyer (e.g., length of time the entrepreneur would be forbidden from starting a new competing company). The goal for the participants was to reach agreement on these issues. Participants completed the exercise face-to-face outside of class, taking an average of about $20 \mathrm{~min}$.

After completing the negotiation, participants completed a survey asking questions about their own and their partner's intentions and 
feelings during the interaction. Participants rated 16 items concerning their own intentions during the interaction (e.g., "I wanted to share helpful information," "I was more interested in getting a good deal than in being a nice person," "I wanted to misrepresent my interests") on a scale ranging from "Not at all" (1) to "Definitely" (6). Participants then rated their partner's intentions on the same items (e.g., "They wanted to share helpful information") using the same scale. Participants also rated their emotions, indicating how a series of adjectives described their feelings during the negotiation. Participants rated 15 items (e.g., angry, resentful, nervous, happy) on a scale ranging from "Not at all" (1) to "Extremely" (6). Participants then rated how the same items described their partner using the same scale.

In addition, participants responded to five items concerning the quality of the interaction. These included satisfaction "with the final outcome and result of this negotiation" and satisfaction "with the quality of the negotiation interaction itself-the quality of the personal exchange you had with your partner," which were rated on a scale ranging from "Extremely dissatisfied" (1) to "Extremely satisfied" (6). Participants also rated two items, "What level of rapport did you feel with your partner" and "Did you feel that you understood what your partner was trying to express," on a scale ranging from "Not much" (1) to "Quite a lot" (6). Further, participants indicated agreement with the item "Do you look forward to future interactions and team-work with your partner," on a scale ranging from "Strongly disagree" (1) to "Strongly agree" (6).

Participants concluded the survey by estimating their performance. First, they estimated their percentile ranking for "gauging what your partner was thinking during the exchange." Next, they estimated their percentile ranking for "gauging what your partner was feeling during the exchange."

\section{Results}

Measures of accuracy were created for each participant by correlating their inferences about their partner (e.g., "They wanted to share helpful information") with the partner's actual self response (i.e., "I wanted to share helpful information"). These correlations were computed across the 16 intention items for a measure of intention accuracy and across the 15 emotion items for a measure of emotion accuracy. These within-participant correlations were then Fisher transformed for between-participant analyses. Again, as a small number of participants did not complete all materials, valid Ns for the reported correlation results range from 134 to 157 . 
Estimated vs. actual performance. As expected, participants' estimates of their performance were modestly or non-significantly correlated with actual performance. The correlation between estimated and actual performance for intuiting intentions was $r=.16(p<.05)$ while for intuiting emotions, it was $r=.12(p=.23, n=164)$.

Pursuing analyses parallel to those reported in Study 1, we found that on average, participants placed themselves in the 61 st percentile in judging intentions and in the 60th percentile in judging emotions. These mean estimates were significantly higher than actual mean percentiles $(\operatorname{ts}(164)=$ 10.2 and 8.7 , respectively, $p s<.001$ ).

As expected, participants in the bottom quartiles dramatically overestimated their performance. People who were the poorest at intentionreading and emotion-reading expected to average in the 60th percentile, when they actually averaged in the 12th $(D s=47.7$ and 47.5 , respectively, $t_{s}(40)=19.8$ and 19.3, ps $\left.<.001\right)$. As in Study 1, the mean estimates for these groups significantly differed from $50 \%(\operatorname{ts}(40)=4.9$ and 4.0, ps <.001), indicating that they saw themselves as significantly "above average." In contrast, people in the top quartiles underestimated their performance, expecting to fall in the 62nd (intention-reading) or 64th percentile (emotion-reading) when in fact they averaged in the 88th percentile $(D s=-24.0$ and $-25.7, t s(40)=-10.1$ and -8.9 , $p s<$ $.001)$.

Narcissism and estimated performance. As predicted, although estimated performance was unrelated to actual performance, those high in narcissism were more likely to see themselves as adept relative to their peers in reading their partner's intentions $(r=.28, p<$ $.01, n=156)$ and emotions $(r=.18, p<.05)$. High self-monitors were also likely to estimate their performance highly for intentions $(r=.20$, $p<.05)$ and emotions $(r=.18, p<.05)$. Extraversion, self-esteem, AQ social skill, and gender were unrelated to participants' sense of mind reading competence in this study. These results are summarized in Table 2 .

After controlling for all other individual difference measures, narcissism remained predictive of estimated intention-reading (partial $r=.27$, $p<.01$ ) and marginally predictive of estimated emotion-reading (partial $r$ $=.16, p=.07)$.

Narcissism, actual performance, and self-awareness. As in Study 1, and consistent with prior work on the topic, neither narcissism nor any of our other measures predicted actual interpersonal sensitivity (see Table 2). 
TABLE 2

\section{Individual Difference Correlates of Estimated and Actual Negotiation Mind-Reading (Study 2)}

\begin{tabular}{|c|c|c|c|c|}
\hline \multirow[b]{3}{*}{ Measure } & \multicolumn{4}{|c|}{ Correlations } \\
\hline & \multicolumn{2}{|c|}{ Estimated percentiles } & \multicolumn{2}{|c|}{ Actual percentiles } \\
\hline & Intentions & Emotions & Intentions & Emotions \\
\hline Narcissism & $.28^{*}$ & $.18^{*}$ & .07 & .01 \\
\hline Self-Monitoring & $.20^{*}$ & $.18^{*}$ & .07 & .05 \\
\hline Sensitivity-to others & $.18^{*}$ & $.22 * *$ & .13 & .09 \\
\hline Self-presentation & $.15^{* * *}$ & .09 & .00 & .01 \\
\hline Extraversion & .05 & .10 & .05 & -.02 \\
\hline AQ social skill & .09 & .14 & .05 & .05 \\
\hline Self-esteem & .07 & -.12 & .06 & -.03 \\
\hline Gender $^{\mathrm{a}}$ & .03 & .02 & .03 & .05 \\
\hline
\end{tabular}

Further, narcissism was not associated with self-awareness, as illustrated in Figure 2. Parallel to the results in Study 1, in multiple regression models predicting estimated performance for emotion-reading and intention-reading, the interaction terms of narcissism and actual performance were not significant ( $p s=.14$ and .29 , respectively). If high narcissists were less self-aware than low narcissists, these interaction terms would have been significant and negative.

Narcissism was also not significantly related to a difference measure of estimated-minus-actual performance for either emotion-reading or intention-reading ( $r=.05$ and .08 , respectively; $n s)$. As can be seen in Figure 2, low performing narcissists appeared to be less well calibrated than non-narcissists while high performing narcissists appeared to be better calibrated than non-narcissists. As a result, there was no overall effect of narcissism on calibration.

Impact of sensitivity. To see whether actual sensitivity "mattered," we considered how estimated and actual percentiles predicted self and partner ratings of interaction quality. The five interaction quality items 
JOURNAL OF NONVERBAL BEHAVIOR
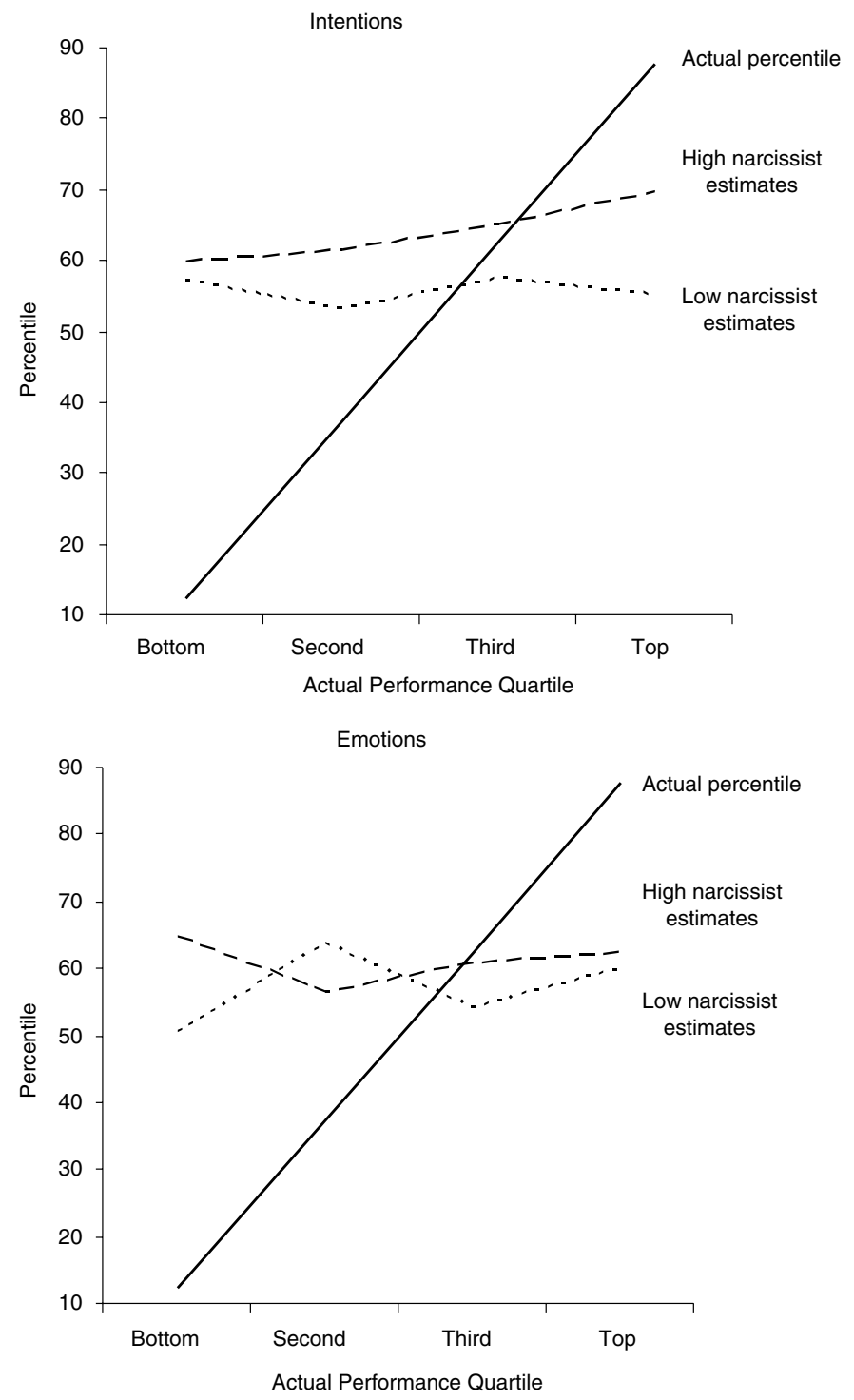

Figure 2. Estimated and actual performance in reading partner's intentions and emotions (Median Split in Narcissism, Study 2). 
TABLE 3

\section{Outcome Correlates of Estimated and Actual Negotiation Mind-Reading (Study 2)}

\begin{tabular}{|c|c|c|c|c|}
\hline \multirow[b]{3}{*}{ Measure } & \multicolumn{4}{|c|}{ Correlations } \\
\hline & \multicolumn{2}{|c|}{ Estimated percentiles } & \multicolumn{2}{|c|}{ Actual percentiles } \\
\hline & Intentions & Emotions & Intentions & Emotions \\
\hline $\begin{array}{l}\text { Self-reported } \\
\text { interaction quality }\end{array}$ & $.21^{*}$ & $.26^{*}$ & $.40^{* *}$ & $.23^{*}$ \\
\hline $\begin{array}{l}\text { Partner-reported } \\
\text { interaction quality }\end{array}$ & .05 & .13 & $.33^{* *}$ & $.25^{*}$ \\
\hline
\end{tabular}

described above (e.g., looking forward to future interactions, team-work with partner) yielded a coherent index of interaction quality, $\alpha=.82$. These items were averaged accordingly. As shown in Table 3, both estimated and actual performance predicted each participant's own ratings of interaction quality but only actual sensitivity predicted partner ratings of quality. In other words, even though participants were more or less unable to judge when they had achieved accuracy, their actual sensitivity mattered, having an impact on the partner's judgment of the interaction quality.

Because most students participated in both Studies 1 and 2, estimates and actual performance could be compared across the studies. The results in Table 4 suggest that the two tasks tapped different interpersonal skills-accuracy in the IPT task did not predict accuracy in reading partners' intentions $(r=-.05, n s, n=139)$ or emotions $(r=.05, n s)$ for the negotiation. On the other hand, accuracy in the two negotiation judgments was modestly correlated $(r=.21, p<.01, n=163)$. Despite the lack of association between accuracy in the IPT and negotiation tasks, there was a pronounced positive correlation between participant estimates of their own accuracy across studies ( $r$ s ranged from .30 to .63, ps $<.001)$. Thus participants who thought they accurately judged the 15 IPT scenarios were also likely to think they could read their partners' 
TABLE 4

Correlating Estimated and Actual Accuracy Across Studies $1 \& 2$

\begin{tabular}{|c|c|c|c|c|c|c|}
\hline & \multicolumn{3}{|c|}{ Estimated Percentiles } & \multicolumn{3}{|c|}{ Actual Percentiles } \\
\hline & $\begin{array}{c}\text { Study } 1 \\
\text { IPT }\end{array}$ & $\begin{array}{c}\text { Study } 2 \\
\text { intentions }\end{array}$ & $\begin{array}{c}\text { Study } 2 \\
\text { emotions }\end{array}$ & $\begin{array}{c}\text { Study } 1 \\
\text { IPT }\end{array}$ & $\begin{array}{c}\text { Study } 2 \\
\text { intentions }\end{array}$ & $\begin{array}{c}\text { Study } 2 \\
\text { emotions }\end{array}$ \\
\hline \multicolumn{7}{|c|}{ Estimated Percentiles } \\
\hline Study 1 IPT & 1.00 & & & & & \\
\hline $\begin{array}{l}\text { Study } 2 \\
\quad \text { intentions }\end{array}$ & $.30^{*}$ & 1.00 & & & & \\
\hline $\begin{array}{l}\text { Study } 2 \\
\quad \text { emotions }\end{array}$ & $.40^{*}$ & $.63^{*}$ & 1.00 & & & \\
\hline \multicolumn{7}{|c|}{ Actual Percentiles } \\
\hline Study 1 IPT & .15 & .03 & .11 & 1.00 & & \\
\hline $\begin{array}{l}\text { Study } 2 \\
\quad \text { intentions }\end{array}$ & -.04 & $.16^{* *}$ & .12 & -.05 & 1.00 & \\
\hline $\begin{array}{l}\text { Study } 2 \\
\quad \text { emotions }\end{array}$ & -.08 & .04 & .05 & .05 & $.21^{* *}$ & 1.00 \\
\hline
\end{tabular}

intentions and emotions in an interpersonal negotiation, irrespective of their actual performance in either task.

\section{Discussion}

Using a face-to-face negotiation interaction, Study 2 revealed no connection between self-estimated performance and actual performance for reading partner emotions and only a weak connection for reading partner intentions. As expected, those who did worst in actual performance substantially overestimated their ability. Integrating the results from Studies 1 and 2, we found that actual performance between the studies was not related but that estimates of performance were. These estimates of performance in Study 2 were, like those in Study 1, predicted by narcissism. Narcissism had the overall effect of increasing estimated performance but appeared to be uncorrelated with self-awareness.

Study 2 also showed that actual sensitivity, but not self-estimated sensitivity, was predictive of partner satisfaction with the interaction. 


\section{Conclusion}

Do we know when we misread minds? Can we effectively gauge our own interpersonal sensitivity - and do those of us who are the least sensitive recognize our limitations? The results of our studies paint a somewhat distressing picture but also give reasons for optimism. Consistent with work elsewhere on metacognition (e.g., Dunning et al., 2003) and on empathic accuracy (e.g., Davis \& Kraus, 1997; Ickes, 1993; Realo et al., 2003), we find that people are poor judges of their own interpersonal sensitivity and mind-reading. Across multiple tasks, featuring controlled video stimuli as well as face-to-face interactions, including measures of sensitivity to lies, relationships, status, motives, and emotions, we found only weak or non-significant correlations between self-estimates of performance and actual performance.

More specifically, our studies confirmed our predictions on two major questions: first, do the least sensitive judges substantially overestimate their performance (we expected them to do so) and, second, what is the source of self-estimates (we believed narcissism would play a role). On this first issue, we found that those in the lowest quartile in interpersonal sensitivity greatly overestimated their relative ability, often by as much as 40 or more percentile points. Indeed, across our tasks, $85-90 \%$ of participants in the lowest quartile thought they were at or above average. Thus, those who were the least sensitive in our tasks were also substantially ignorant of their limitations. This fits with work by metacognition researchers (e.g., Dunning et al., 2003) but appears to be the first reported evidence of this effect in the domain of interpersonal sensitivity.

We also considered the sources of self-estimated performance. Across three tasks (the IPT-15 as well as the emotion and intention judgments for the negotiation partner), we found limited correlations for actual sensitivity: emotion- and intention-reading were modestly linked but neither was related to performance on the IPT-15 (see Table 4). Nonetheless, self-estimates of performance were strongly linked across the three tasks, suggesting that some kind of systematic mechanism, rather than guesswork, was at work.

We considered self-views that were focused on the domain of interpersonal sensitivity (e.g., self-monitoring) as well as narcissism, the general tendency to self-aggrandize. Consistent with prior work (Davis \& Kraus, 1997; Ehlringer \& Dunning, 2003;), we found some effects for the domain-specific self-reports of self-monitoring. In all three tasks, self-monitoring, especially the "sensitivity to others" component, predicted self-estimates of interpersonal judgment ability. However, we 
expected independent effects of narcissism. In all three tasks, this was borne out: narcissism predicted self-estimated performance, even after controlling for self-monitoring and other domain-specific constructs. This connection between general self-aggrandizing tendencies and views of particular performances is consistent with other work on narcissism (e.g., John \& Robins, 1994; Paulhus, 1998), though our evidence appears to be the first focusing on interpersonal sensitivity.

This somewhat bleak portrait of seemingly widespread ignorance about one's own interpersonal sensitivity may yield reasons to be hopeful_or at least signals about which interventions may be most promising. Kruger and Dunning (1999) showed that even brief training in a domain (in their case, logical reasoning) improved people's ability to diagnose competence in the domain. Thus, the challenge in helping the insensitive improve may often not be a case of motivating them to care but rather a case of providing feedback to stimulate awareness and training to improve competence.

Another perspective comes from recent work by Burson, Larrick, and Klayman (2004). They suggest that performance estimates are partly driven by perceived task difficulty: on easier tasks, most people overestimate their performance (leading to an above-average effect, as in our results) while on harder tasks, most people underestimate their performance (leading to a below-average effect). Thus, on seemingly harder tasks, those who actually perform worst may appear better calibrated than those who do best. For our results, this work on apparent task difficulty implies that most perceivers may regard interpersonal judgment ("Is she lying?," "Does he want to help me?," "Is she bored?") as a relatively easy task-perhaps easier than it is. Thus, increasing sensitivity may not only be a matter of improving performance, but also of highlighting the challenges and difficulty of interpersonal sensitivity.

We should note, briefly, that pursuing awareness-raising interventions with narcissists may require extreme care. Delivering feedback is almost always precarious, and particularly so with narcissists who have been described as "grandiose, yet fragile" (Morf \& Rhodewalt, 2001) and who, when informed of failure, tend to become angry, hostile, aggressive, and derogatory (e.g., Bushman \& Baumeister, 1998; Kernis \& Sun, 1994).

Our work also features a number of noteworthy null results. None of our individual difference measures meaningfully predicted actual accuracy in any of our social judgment tasks. These results depart from prior work that finds effects of gender (see Ickes, Gesn, \& Graham, 2000 for a discussion of ability and motivational differences in empathic accuracy) and self-monitoring (e.g., Davis \& Kraus, 1997). We also found that the 
social skills subscale of Baron-Cohen and colleagues' Autism-Spectrum Quotient (Baron-Cohen et al., 2001) did not predict actual sensitivity. Our results cannot discriminate if these non-significant correlations are due to sample (e.g., restricted range), the fallibility of self-reports, or some other factor.

Finally, there has been some suggestion that narcissists may be worse at perspective-taking and social judgment (e.g., Watson, et al., 1984). However, we found no evidence of a negative relationship between narcissism and actual interpersonal sensitivity. We also found no evidence of either a positive or negative relationship between narcissism and self-awareness. In both studies, narcissism was not associated with overestimation of one's performance or with an increased (or decreased) connection between actual and estimated performance. One reason for this is that, like other low and high performers, low performing narcissists overestimated their performance while high performing narcissists underestimated their performance (see Figures 1 and 2).

We also want to underscore that our results highlight the importance of interpersonal sensitivity. Even though our participants were not very successful at gauging their performances, accuracy had significant consequences. In Study 2, actual ability to detect a partner's intentions and emotions was significantly related to the partner's reports of interaction quality (e.g., looking forward to future interactions and team-work with the participant). Thus, one could imagine a scenario in which an actor feels she has thoroughly "read" her partner, but her actual dismal understanding leaves her partner unenthused about future interaction. As a result, both parties' expectations about future encounters (both their likelihood and quality) could be substantially misaligned. Beyond perceptions and expectations, such partners could face increased difficulty in resolving conflicts because they may lack a mutual sense of rapport (e.g., Drolet \& Morris, 2000).

In conclusion, we believe that interpersonal sensitivity is a competence that is not only critical to everyday life and well-being, but also one that can be cultivated, depending on an awareness of one's ability. Our research here highlights the challenge we all face in attaining such awareness - and the fact that much of the time, we may overestimate ourselves. As a result, we might frequently overlook chances to improve our social competence, both in specific episodes and in terms of our more generalized sensitivity. Our findings suggest that researchers hoping to improve people's interpersonal accuracy should focus on (1) people's basic abilities that allow them to make sound judgments and discriminate good from bad performances and (2) people's motivations 
and self-views that can interfere with self-awareness about such performances.

\section{Notes}

1. The size of these quartiles was uneven because of the distribution of participant performance on the task. The reported top and bottom quartiles reflect absolute performance of 3-8 and 12-14, respectively, on the 15-point IPT task, which most closely approximated quartiles. Expanding, contracting, and shifting the cut-offs yielded the same pattern of results.

\section{References}

Alicke, M. D. (1985). Global self-evaluation as determined by the desirability and controllability of trait adjectives. Journal of Personality and Social Psychology, 49, $1621-1630$.

Ames, D. R., Rose, P., \& Anderson, C. P. (2004). Narcissism: A 16 item-pair scale. Manuscript under review.

Baron-Cohen, S., Wheelwright, S., Skinner, R., Martin, J., \& Clubley, E. (2001). The AutismSpectrum Quotient (AQ): Evidence from Asperger syndrome/high-functioning autism, males and females, scientists and mathematicians. Journal of Autism and Developmental Disorders, 31, 5-17.

Burson, K. A., Larrick, R. P., \& Klayman, J. (2004). Skilled or unskilled, but still unaware of it: How perceptions of difficulty drive miscalibration in relative comparisons. Manuscript under review.

Bushman, B. J., \& Baumeister, R. F. (1998). Threatened egotism, narcissism, self-esteem, and direct and displaced aggression: Does self-love or self-hate lead to violence? Journal of Personality and Social Psychology, 75, 219-229.

Colvin, C. R., \& Block, J. (1994). Do positive illusions foster mental health? An examination of the Taylor and Brown formulation. Psychological Bulletin, 116, 3-20.

Costanzo, M., \& Archer, D. (1989). Interpreting the expressive behavior of others: The interpersonal perception task. Journal of Nonverbal Behavior, 13, 225-235.

Costanzo, M., \& Archer, D. (Producers) (1993). Interpersonal perception task-15 [videotape]. University of California Extension Center for Media and Independent Learning, 2000 Center Street, Berkeley, CA 94704.

Davis, M. H., \& Kraus, L. A. (1997). Personality and empathic accuracy. In W. Ickes (Ed.), Empathic accuracy (pp. 144-168). New York: Guilford Press.

DePaulo, B. M., Charlton, K., Cooper, H., Lindsay, J. J., \& Muhlenbruck, L. (1997). The accuracy-confidence correlation in the detection of deception. Personality and Social Psychology Review, 1, 246-357.

Drolet, A. L., \& Morris, M. W. (2000). Rapport in conflict resolution: Accounting for how nonverbal exchange fosters cooperation on mutually beneficial settlements to mixedmotive conflicts. Journal of Experimental Social Psychology, 36, 26-50.

Dunning, D., Johnson, K., Ehrlinger, J., \& Kruger, J. (2003). Why people fail to recognize their own incompetence. Current Directions in Psychological Science, 12, 83-87.

Dunning, D., Meyerowitz, J., \& Holzberg, A. D. (1989). Ambiguity and self-evaluation: The role of idiosyncratic trait definitions in self-serving assessments of ability. Journal of Personality and Social Psychology, 57, 1082-1090. 
Ehrlinger, J., \& Dunning, D. (2003). How chronic self-views influence (and potentially mislead) estimates of performance. Journal of Personality and Social Psychology, 84, 5-17.

Ekman, P., \& O'Sullivan, M. (1991). Who can catch a liar? American Psychologist, 46, 913920.

Emmons, R. A. (1987). Narcissism: Theory and measurement. Journal of Personality and Social Psychology, 52, 11-17.

Gabriel, M. T, Critelli, J. W., \& Ee, J. S. (1994). Narcissistic illusions in self-evaluations of intelligence and attractiveness. Journal of Personality, 62, 143-155.

Hodges, S. D. (2003). Is how much you understand me in your head or mine? Paper presented at Other Minds: An Interdisciplinary Conference, University of Oregon, Eugene, OR.

Ickes, W. (2003). Everyday mind reading: Understanding what other people think and feel. Amherst, NY: Prometheus Books.

Ickes, W. (1993). Empathic accuracy. Journal of Personality, 61, 587-610.

Ickes, W., Gesn, P. R., \& Graham, T. (2000). Gender differences in empathic accuracy: Differential ability or differential motivation? Personal Relationships, 7, 95-109.

John, O. P., Donahue, E. M., \& Kentle, R. (1991). The Big-Five Inventory. Technical Report, Institute for Personality and Social Research, University of California, Berkeley, CA.

John, O. P., \& Robins, R. W. (1994). Accuracy and bias in self-perception: Individual differences in self-enhancement and the role of narcissism. Journal of Personality and Social Psychology, 66, 206-219.

Kernis, M. H., \& Sun, C. R. (1994). Narcissism and reactions to interpersonal feedback. Journal of Research in Personality, 28, 4-13.

Kruger, J., \& Dunning, D. (1999). Unskilled and unaware of it: How difficulties in recognizing one's own incompetence lead to inflated self-assessments. Journal of Personality and Social Psychology, 77, 1121-1134.

Lennox, R. D., \& Wolfe, R. N. (1984). Revision of the self-monitoring scale. Journal of Personality and Social Psychology, 46, 1349-1364.

Morf, C. C., \& Rhodewalt, F. (2001). Unraveling the paradoxes of narcissism: A dynamic self-regulatory processing model. Psychological Inquiry, 12, 177-196.

Patterson, M. L., \& Stockbridge, E. (1998). Effects of cognitive demand and judgment strategy on person perception accuracy. Journal of Nonverbal Behavior, 22, 253-263.

Patterson, M. L., Foster, J. L., \& Bellmer, C. (2001). Another look at accuracy and confidence in social judgments. Journal of Nonverbal Behavior, 25, 207-219.

Paulhus, D. L. (1998). Interpersonal and intrapsychic adaptiveness of trait self-enhancement: A mixed blessing? Journal of Personality and Social Psychology, 74, 1197-1208.

Paulhus, D.L., Lysy, D.C., \& Yik, M.S.N. (1998). Self-report measures of intelligence: Are they useful as proxy IQ tests? Journal of Personality, 66, 525-554.

Realo, A., Allik, J., Nolvka, A., Valk, R., Ruus, T., Schmidt, M., \& Eilola, T. (2003). Mind reading ability: Beliefs and performance. Journal of Research in Personality, 37, 420-445.

Robins, R.W., Hendin, H. M., \& Trzesniewski, K. H. (2001). Measuring global self-esteem: Construct validation of a single-item measure and the Rosenberg Self-Esteem Scale. Personality and Social Psychology Bulletin, 27, 151-161.

Robins, R.W., \& John, O.P. (1997). Effects of visual perspective and narcissism on self-perception: Is seeing believing? Psychological Science, 8, 37-42.

Smith, H. J., Archer, D., \& Costanzo, M. (1991). "Just a hunch": Accuracy and awareness in person perception. Journal of Nonverbal Behavior, 15, 3-18.

Swann, W. B., Jr., \& Gill, M. J. (1997). Confidence and accuracy in person perception: Do we know what we think we know about our relationship partners? Journal of Personality and Social Psychology, 73, 747-757.

Taylor, S.E., \& Brown, J. (1988). Illusions and well-being: A social-psychological perspective on mental health. Psychological Bulletin, 103, 193-210.

Watson, P. J., Grisham, S. O., Trotter, M. V., \& Biderman, M. D. (1984). Narcissism and empathy: Validity evidence for the Narcissistic Personality Inventory. Journal of Personality Assessment, 48, 301-305. 